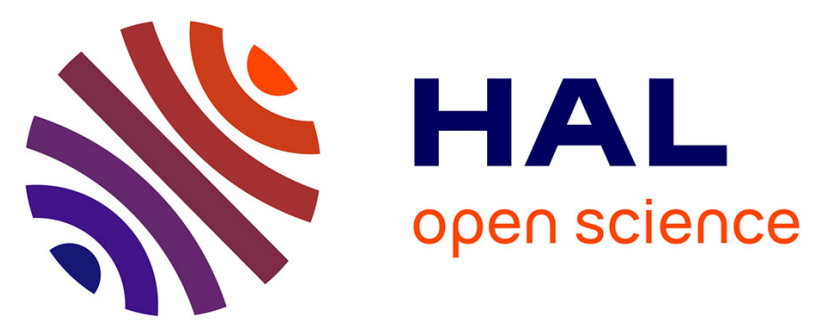

\title{
Geomorphic Change Detection Using Cost-Effective Structure-from-Motion Photogrammetry: Evaluation of Direct Georeferencing from Consumer-Grade UAS at Orewa Beach (New Zealand)
}

\author{
Stéphane Bertin, Benjamin Levy, Trevor Gee, Patrice Delmas
}

\section{To cite this version:}

Stéphane Bertin, Benjamin Levy, Trevor Gee, Patrice Delmas. Geomorphic Change Detection Using Cost-Effective Structure-from-Motion Photogrammetry: Evaluation of Direct Georeferencing from Consumer-Grade UAS at Orewa Beach (New Zealand). Photogrammetric engineering and remote sensing, 2020, 86, pp.289 - 298. 10.14358/pers.86.5.289 . hal-03470786

\author{
HAL Id: hal-03470786 \\ https://hal.science/hal-03470786
}

Submitted on 8 Dec 2021

HAL is a multi-disciplinary open access archive for the deposit and dissemination of scientific research documents, whether they are published or not. The documents may come from teaching and research institutions in France or abroad, or from public or private research centers.
L'archive ouverte pluridisciplinaire HAL, est destinée au dépôt et à la diffusion de documents scientifiques de niveau recherche, publiés ou non, émanant des établissements d'enseignement et de recherche français ou étrangers, des laboratoires publics ou privés.

\section{(1) (1) $\$$}

Distributed under a Creative Commons Attribution - NonCommercial - NoDerivatives 44.0 


\title{
Geomorphic Change Detection Using Cost- Effective Structure-from-Motion Photogrammetry: Evaluation of Direct Georeferencing from Consumer-Grade UAS at Orewa Beach (New Zealand)
}

\author{
Stephane Bertin, Benjamin Levy, Trevor Gee, and Patrice Delmas
}

\begin{abstract}
Unmanned aerial systems (UAS) and structure-from-motion photogrammetry are transforming the way we produce topographic data, with applications covering many disciplines in the geosciences, including coastal studies. To overcome limitations of ground control points (GCPS), we evaluate direct georeferencing ( $D G$ ) of consumer UAS imagery for the cost-effective measurement of beach topography. Using $D G$, camera positions determined with on-board instruments provide air control points for photogrammetry, obviating the need for presurveyed GCPs. We validate the approach at Orewa Beach, New Zealand, achieving vertical accuracies similar to light detection and ranging $(<0.2 \mathrm{~m})$ at a higher resolution $(<0.1 \mathrm{~m})$. A low-quality global navigation satellite system onboard a consumer UAS remains the main constraint on measurement quality. We show how independent topographic data sets, which are increasingly available worldwide, can improve measurement quality, and hence change detection capacity. Our understanding of measurement quality achieved in this study is applied to the assessment of morphological and volumetric change at Orewa Beach.
\end{abstract}

\section{Introduction}

The coast is a dynamic and fragile environment, and measurements of the coastal zone should ideally reflect this temporality if we aim to understand the (geomorphic) processes and changes that occur in response to natural and anthropogenic drivers. Developments in topography remote sensing (e.g., image-based and laser scanning techniques) have greatly improved our ability to survey the coast at a large scale allowing, for example, to transition from labor-intensive beach profiles to digital surface models (DSMs), with higher resolution and surface coverage. In New Zealand, airborne lidar (light detection and ranging) was used to survey the Auckland isthmus in 2013, resulting in topographic data covering over 2000 $\mathrm{km}^{2}$ and including most of the coastal zone (LINZ 2019). Such data sets are increasingly valuable for detailed coastal flood

Stephane Bertin is with the Institut Universitaire Européen de la Mer (IUEM), Univ. Brest, Laboratoire Géosciences OcéanUMR 6538, Technopôle Brest-Iroise, Rue Dumont d'Urville, F-29280 Plouzané, France (s.bertin@ymail.com).

Stephane Bertin and Benjamin Levy are with EPhoS Limited, Lorne Street, NZ-1010 Auckland, New Zealand.

Trevor Gee and Patrice Delmas are with the Department of Computer Science, The University of Auckland, Princes Street, NZ-1010 Auckland, New Zealand. risk analyses (Raji et al. 2011), providing coastal managers with essential information for adapting coastal areas to storm events and rising sea levels (e.g., Ministry for the Environment 2015; National Institute of Water and Atmosphere 2015). However, the cost for lidar data acquisition remains high, and thus seldom enables repeated measurements to monitor coastal change, such as rapid storm-induced erosion or even annual/pluriannual evolution.

A growing alternative in topographic remote sensing is the use of (small) unmanned aerial systems (UAS), commonly referred to as drones, equipped with photographic sensors. With cost-effective technologies that continue to improve, UAS are increasingly accessible and versatile, allowing the capture of aerial imagery in a variety of situations. Compared with full-scale airborne platforms, UAS provide the opportunity of frequent data capture at a very low cost, with sampling periods that can be virtually as low as minutes or hours. Furthermore, adapting flight plans and image acquisition geometries to the terrain and study needs has become relatively straightforward using drones, which can improve survey resolution and precision. Parallel developments in Computer Vision, for instance by reducing previous constraints on stereo correspondence and by reducing uncertainty in photogrammetry (Lane, James, and Crowell 2000) have resulted in the rapid uptake of UAS-based photogrammetry in scientific studies. Particularly, structure-from-motion (SfM) and multi-view stereo algorithms (Lowe 2004; Furukawa and Ponce 2010) allow the production of high-quality DSMs and orthophotographs from imagery collected with different orientations and scales using consumer (nonmetric) cameras. This photogrammetric approach is commonly referred to as SfM photogrammetry.

Although using UAS and SfM photogrammetry in combination is becoming widespread in scientific studies to measure topography (see, e.g., the review by Colomina and Molina 2014), with several applications to the coastal zone (e.g., Mancini et al. 2013; Ierodiaconou, Schimel, and Kennedy 2016; Long et al. 2016; Turner, Harley, and Drummond 2016; Talavera et al. 2018; Laporte-Fauret et al. 2019), we argue that further methodological development is necessary to the larger uptake of the technique and increased accessibility, including outside academic disciplines. In particular, methodologies

Photogrammetric Engineering \& Remote Sensing Vol. 86, No. 5, May 2020, pp. 289-298.

0099-1112/20/289-298

(C) 2020 American Society for Photogrammetry and Remote Sensing doi: 10.14358/PERS.86.5.289 
using consumer-grade UAS, and that do not require ground control points (GCPs), could significantly improve current data collection strategies associated with SfM photogrammetry. A solution suggested by previous research is to develop so-called direct georeferencing (DG), whereby knowledge of camera positions (X, Y, and Z) and orientations (pitch, roll, and yaw) at the time of image acquisition is sufficient to georeference and scale photogrammetric measurements (Carbonneau and Dietrich 2017). Compared to photogrammetric approaches requiring GCPs, the advantages of DG are clear. By removing ground control (e.g., targets distributed on the site and independently measured), professional survey equipment (e.g., real-time kinematic-global positioning system (RTK-GPS) or total station) is no longer required, which could dramatically reduce the time and resource demands for UAS photogrammetry. Furthermore, using DG, foot-access to the survey area would not be required, which in the case of hazardous or inaccessible areas would facilitate high-quality topographic monitoring. To allow widespread applications of DG, research must determine if visual odometry in combination with onboard sensors, such as GPS and inertial measurement unit, can achieve results to the level that GCPs are no longer necessary.

DG of SfM photogrammetry has only been investigated by a few studies to date, with none clearly demonstrating the potential of DG from consumer-grade UAS to monitor beach morphological change. Turner, Lucieer, and Wallace (2014) developed a purpose-built UAS and GPS module and showed that DG can produce georeferenced orthophotographs suitable for agricultural applications (horizontal precision $\sim 0.1 \mathrm{~m}$ ). Jaud et al. (2018) used directly georeferenced hyperspectral images obtained from HyperDrelio, a purpose-built drone for environmental applications, to measure submerged topographies of a sandy beach and lake. Carbonneau and Dietrich (2017) presented evaluations of DG over small test fields and provided recommendations to improve data quality by comparing different image acquisition geometries (i.e., different flight plans and image orientations). Another application over structurally complex badland surfaces showed that DG can result in survey precision similar with surveys using GCPs, even when precision in camera position is half as good as GCPs' (James et al. 2017). All these studies support the idea that DG of SfM photogrammetry is a valid endeavor and that high-quality data can be obtained at a fraction of the time and cost commonly associated with standard photogrammetric approaches requiring GCPs.

In this paper, we test the applicability of DG in a coastal environment to assess morphological change, using the south end of Orewa Beach (New Zealand) as a field laboratory. Using popular consumer-grade UAS and photogrammetric software, we produced DSMs and orthophotos of the study area in 2018. The availability of a lidar data set obtained in 2013 provided means to assess measurement quality and morphological changes of the beachface and dune between the two surveys. Results show that vertical accuracies similar to lidar can be achieved using DG, at a higher resolution. However, the adoption of a detailed error assessment procedure reveals systematic errors, taking the form of linear shifts and geometric distortions of small magnitude (typical standard deviation $\sim 0.2 \mathrm{~m}$ ). These errors result from camera position and calibration errors, which can propagate and affect the reliability of findings. We show how independent topographic data sets such as lidar, which are increasingly available to determine vertical coordinates worldwide, can improve measurement accuracy and hence the reliability of geomorphic change detection using DG. The results produced in this paper represent a step forward towards proposing a simple, affordable, and effective technique that can be implemented by all for measuring the topography of continental surfaces, including, but not limited to, coastal systems.

\section{Materials and Methods}

\section{Study Area and Context}

A pilot study was conducted at Orewa Beach (Figure 1a), on the northeastern shoreline of North Island, New Zealand. Orewa is representative of the beaches northeast of Auckland and is the subject of a monitoring program by the local council. Orewa is a relatively straight, gently sloping, and meso-tidal beach, with an estuary mouth before a small headland to the south, and a small stream and a larger headland to the north. The coast around Orewa is protected by offshore islands and the Coromandel peninsula. Generally, waves are small, short period seas, created by fetch limited local winds. The coast occasionally receives storm waves and larger swell from the North through to the East, especially when posttropical depressions drop east of New Zealand.
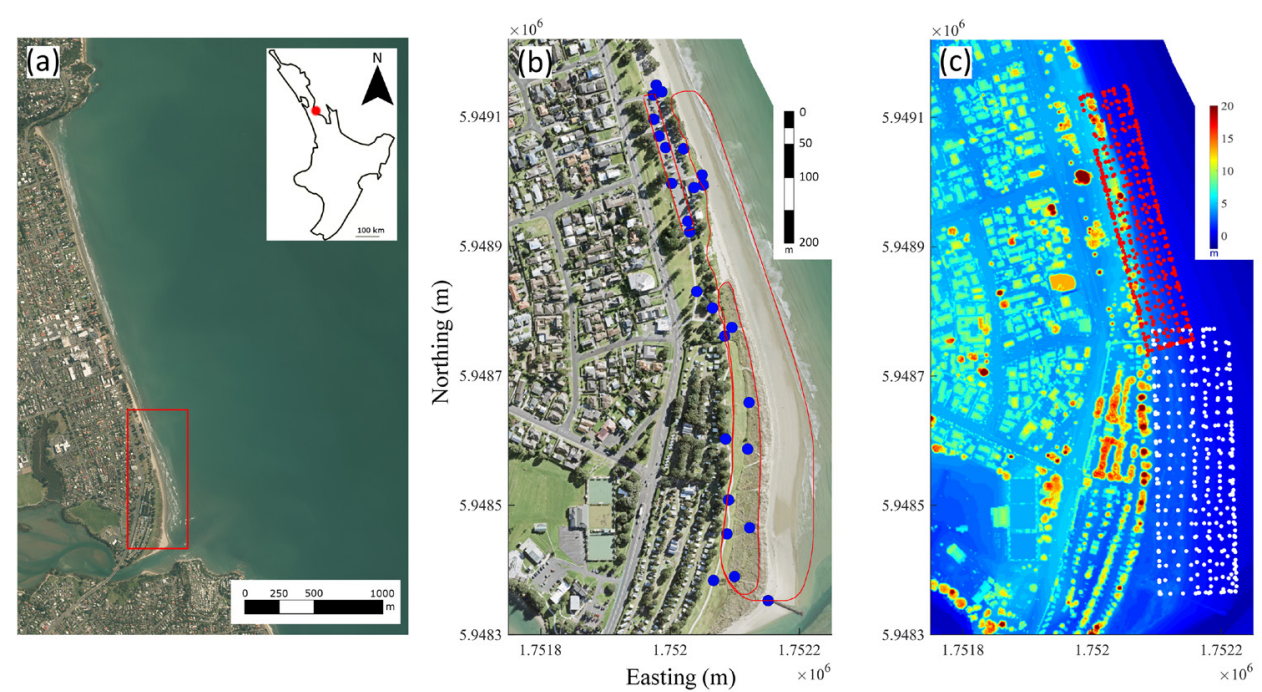

Figure 1. (a) Location of the study area at the south end of Orewa Beach, North Island, New Zealand. (b) Orthophoto (GSD $=0.125 \mathrm{~m}$ ) provided by LINZ; red polygons indicate different regions of interest (see text for information) and blue dots correspond to lidar-derived control points (CtrlPts). (c) 2013 lidar DSM (grid spacing = $1 \mathrm{~m}$ ) where white and red dots indicate camera position for UAS photogrammetry. Coordinates are reported in the local coordinate system (horizontal: NZGD2000, elevation: NZVD2009). All dimensions are in meters. 
Sediment on the beach is a mix of fine sand and silt, with a median grain size $\mathrm{D}_{50}$ of $0.13 \mathrm{~mm}$ (Raudkivi 1981). The beach was originally backed by low sand dunes, which acted as a buffer zone during storms and provided sand for natural replenishment. Following increasing human intervention from the 1950s (e.g., sand mining for construction, realignment of the south estuary channel, and construction of a groyne along the estuary mouth), dunes only remain at the southern end where our survey area is located (Figure 1b), while rip-rap seawalls now make for most of the beach length. These changes have resulted in significant erosion of the sand on the beachface, such that there is virtually no beach at high tide and beachfront properties are often at risk during storms and perigean spring tides. In response, a sand replenishment program was started in 1988. The latter is done every year, generally in spring, and consists of harvesting the sand deposited at the southern groyne (sediment sink) and placing that sand at the center of the beach. Beach change monitoring has so far been limited to the analysis of three beach profiles collected approximately once a year. In comparison, it is imagined that UAS and SfM photogrammetry could provide the high resolution and high frequency data at a very low cost to monitor the beach morphodynamics at this location to better manage coastal hazards.

\section{Lidar Dataset}

As part of a national effort to have comprehensive lidar coverage across New Zealand, the Auckland region was surveyed in 2013. The data freely accessible online (LINZ 2019) comprise point clouds, DSMs, and digital elevation models (DEMs, with filtered vegetation and buildings) tiled into 1:1000 tile layout and covering approximately $2250 \mathrm{~km}^{2}$ in total. Coordinates are referenced to the NZGD2000 projection system and NZVD2009 as vertical datum. Raster grid spacing for DSMs and DEMs is $1 \mathrm{~m}$, while horizontal and vertical accuracies reported in the metadata are $\pm 0.6 \mathrm{~m}$ and $\pm 0.2 \mathrm{~m}$, respectively (at a $95 \%$ confidence level). For this study, we used three DSMs (az314642, az31-4742, and az31-4743) stitched together in Matlab (see e.g., Bertin, Friedrich, and Delmas 2016) to produce a unique DSM of the study area (Figure 1c). We also used three corresponding georeferenced orthophotos, with a ground sampling distance (GSD) of $0.125 \mathrm{~m}$, to produce a textured DSM of the study area (Figure 1b). The latter provided a benchmark against which photogrammetry was evaluated. In addition, invariant features (e.g., road markings, drains, etc.) identified in the textured DSM formed control points (CtrlPts) for calibration and georeferencing of photogrammetry (see the section "SfM Photogrammetry Processing”).

\section{UAS Platform for SfM Photogrammetry}

UAS deployment was conducted on the morning of 7 September 2018, which was partly cloudy with wind gusts averaging 10-15 knots and increasing. Image collection was timed to coincide with low tide at 10 A.M. The UAS used for the study is a Mavic Pro (MP), manufactured by DJI Inc. The MP is a popular consumer quadcopter with several features of interest for scientific applications. It has an integrated camera (model FC220: 1/2.3" complementary metal-oxide-semiconductor sensor, $26 \mathrm{~mm}$ focal length in $35 \mathrm{~mm}$ format equivalent) mounted on a three-axis gimbal that ensures camera stabilization. Using the camera, we acquired 12-megapixel still imagery in Joint Photographic Experts Group format (JPEG) with a manufacturer stated distortion $<1.5 \%$. The internal Global Navigation Satellite System (GNSS) (GPS/GLONASS) used for navigation and flight stabilization has a stated accuracy of $1.5 \mathrm{~m}$ horizontal and $0.5 \mathrm{~m}$ vertical. GNSS values are automatically exported to the exchangeable image file format (EXIF) metadata in WGS84 latitude and longitude format providing a location stamp (geotag) for each captured image. The battery (3880 mAh Lithium Polymer LiPo 3s) provided the capacity for a 20 minute flight at speeds up to $65 \mathrm{~km} / \mathrm{h}$. The low cost of the now discontinued MP ( NZD1500) makes it accessible, while limiting the impact of a total loss in the event of a crash, allowing for flights in risky environments such as the coastal zone. At the time of writing, its successor the MP2 offers improved specifications, such as a 20-megapixel Hasselblad camera and flight durations up to 30 minutes for a similar price tag.

\section{Flight Plan and Image Acquisition}

The complete DEM collection workflow is presented in Figure 2. The free Pix4Dcapture mobile application was used to prepare the flights over the study area. In total, two 20 minute flights were conducted, allowing the survey of over $800 \mathrm{~m}$ of beach along-shore and $100 \mathrm{~m}$ cross-shore. Images were automatically collected along a grid (Figure 1c) from a flying height of $40 \mathrm{~m}$, with a $65 \%$ front and side overlap and a GSD $\sim 1.4 \mathrm{~cm}$. The survey was repeated at $90^{\circ}$ to the initial flight path (called the double grid approach in Pix4Dcapture) to ensure high data redundancy and to reduce the occurrence of shadowing during three-dimensional (3D) reconstruction. The camera angle was set to $70^{\circ}$ (i.e., $20^{\circ}$ off-nadir) as previous work shows that using convergent imagery in photogrammetry reduces the risk of nonlinear deformations in topographic models (Wackrow and Chandler 2008; James and Robson 2014). In total, 849 geolocated JPEG images were collected during the two flights.

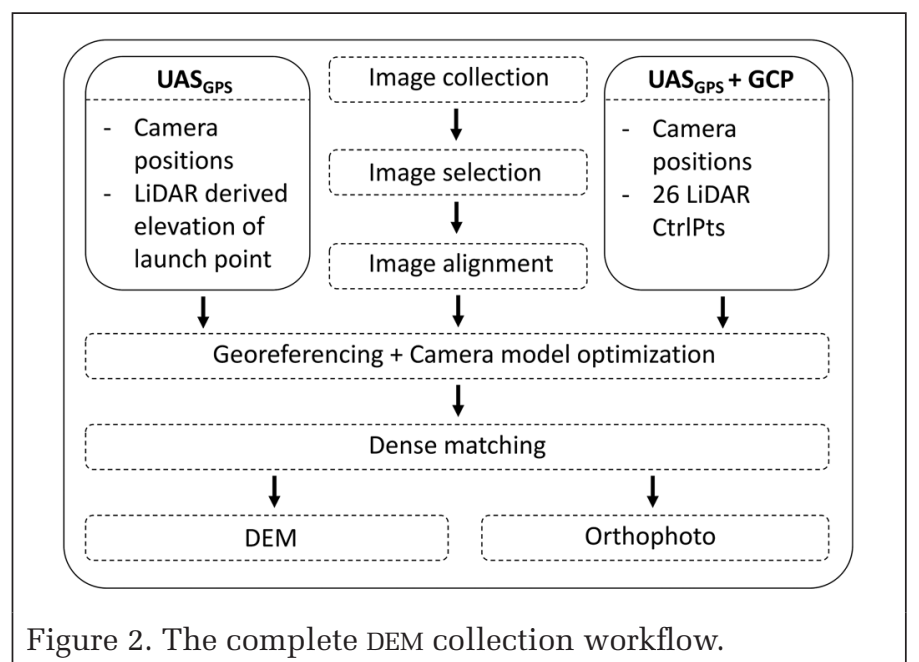

\section{SfM Photogrammetry Processing}

Images were imported into Photoscan Pro (now Agisoft Metashape) as a single "chunk" and their horizontal coordinates were transformed to the local coordinate system NZGD2000. Examination of the EXIF metadata showed that GNSS elevations were systematically offset, indicating a flying height of $9 \mathrm{~m}$. This is a common issue when using consumer UAS (Griffiths and Burningham 2019). Correction was done using the Exiftool by overwriting the EXIF absolute elevation with the EXIF relative elevation measured with the internal barometer, provided the launch elevation was initially set to zero. Following, image quality was estimated using PhotoScan, whereby sharpness values are used to define quality (0 = blurred, 1 = very sharp), and all images with a quality below 0.8 were discarded to retain only the sharpest images. The remaining images (785) were aligned using the high-quality image-alignment setting, followed by a dense reconstruction at a high-density setting. During the image alignment, the program searched for matching features in overlapping photos and optimized the self-calibrated camera intrinsic and extrinsic 
parameters using bundle adjustment from the matched points. Preliminary testing on the sparse point cloud showed that using the intrinsic parameters presented in Table 1 resulted in the best results, in that it improved the reprojection error and no obvious deformation was present in DSMs. The dense point cloud comprised of 75500000 points distributed over 150 $000 \mathrm{~m}^{2}$, corresponding to a point density in excess of 500 points $/ \mathrm{m}^{2}$ (i.e., an average point spacing $\sim 0.05 \mathrm{~m}$ ). The dense point cloud was transformed into a raster DSM with regular point spacing of $0.1 \mathrm{~m}$, and automatically projecting every image pixel onto the DSM produced an orthophoto of the same sampling resolution. To facilitate data processing for sections of interest, several DSMs and orthophotos were produced (cf., Figure 1b) by manually creating shapes in PhotoScan. DSMs and orthophotos were finally exported as .xyz and .tif files, respectively, for analysis in Matlab.

Not using GCPs meant that the elevations measured with photogrammetry were relative to the zero-elevation established at the launch point. To allow comparison with other data sets, elevations were further processed to georeference the model according to the local vertical datum NZVD2009. We used lidar as reference to determine the elevation of the launch point. This value was added to the relative camera elevation. Carbonneau and Dietrich (2017) and Griffiths and Burningham (2019) used similar methods whereby the elevation of the launch point was determined from Shuttle Radar Topography Mission (SRTM) data set and differential Global Positioning System, respectively. This method to establish a vertical datum for SfM photogrammetry is hereafter referred to as $\mathrm{UAS}_{\mathrm{GPS}}$, in that the shape and dimension of the photogrammetric solution is controlled by camera position only (Griffiths and Burningham 2019). A second reconstruction scenario, referred to as UAS $\mathrm{UPS}_{\text {S }}+$ GCP, was also tested (Figure 2). For this method, lidar-derived CtrlPts were used as weighted observations to georeference and optimize calibration parameters during bundle adjustment. 26 CtrlPts were created with the condition that they were easily identifiable with both lidar and photogrammetry, and that they remained unchanged between the two surveys (Figure 1b). Following recommendation from James et al. (2017), we carefully adjusted weighing coefficients for the bundle adjustment using PhotoScan outputted values for the precision of tie points and CtrlPts.

\section{Morphological Change Detection over the Period 2013-2018}

Beach morphological change between 2013 and 2018 was analyzed using the elevation difference (DSM of difference, or DoD) between lidar and photogrammetry in MATLAB. Elevation difference was computed cell-by-cell using the lidar resolution of $1 \mathrm{~m}$. Areas of deposition are indicated by positive DoD values, while areas where the $\mathrm{DoD}$ is negative indicate erosion. The total volumes of deposition and erosion were estimated by integrating the DoD over the area where it is positive and negative, respectively, and the net volume change between the two surveys was calculated as the addition of erosion and deposition volumes.

Application of a minimum level of detection (minLOD) by counting only those differences between DSMs displaying an absolute value larger than the minLOD allowed removing from the calculations the areas where change detected was too little to be considered reliable given the measurement uncertainties (both lidar and photogrammetry). The minLOD was calculated as (Brasington, Langham, and Rumsby 2003):

$$
\operatorname{minLOD}=\mathrm{t} \sqrt{\mathrm{SDE}_{\mathrm{SfM}}^{2}+\mathrm{SDE}_{\text {lidar }}^{2}},
$$

where $\mathrm{t}$ is the confidence level (set to 1.96, representing a $95 \% \mathrm{CI}$ ) and $\mathrm{SDE}_{\mathrm{SfM}}$ and $\mathrm{SDE}_{\text {lidar }}$ are the standard deviation of errors for photogrammetry and lidar, respectively. $\mathrm{SDE}_{\text {lidar }}$ was set to $0.2 \mathrm{~m}$, i.e., the vertical precision of the lidar data set. Measurement quality with SfM photogrammetry can vary largely between studies due to the different hardware, and the data acquisition and processing methods used. A comprehensive error assessment was applied to our measurements (see the section "Error Assessment of SfM Photogrammetry"), from which the metric $\mathrm{SDE}_{\mathrm{SfM}}$ was estimated for use in the minLOD calculation. Using the minLOD, volumetric uncertainty on erosion and deposition volumes was calculated as the number of cells experiencing change (deposition or erosion, respectively), multiplied by the minLOD and the cell area (Ierodiaconou, Schimel, and Kennedy 2016).

\section{Error Assessment of SfM Photogrammetry}

Topographic data produced with SfM photogrammetry can present systematic error patterns (Figure 3) that cannot be explicitly represented using a single statistic such as mean error (ME) or root-mean-square error. For instance, errors in camera position can propagate as errors of position, orientation, and/or scale in the model. In addition, errors in the calibrated camera parameters can result in nonlinear deformations generally taking the form of doming or dishing (Figure 3 ). Each of these errors can potentially impact change detection, for instance by creating false horizontal or vertical offsets (position/translation errors), or by producing incorrect tilts or warps. Rigorous characterization of measurement error is critical to ensure reliable comparisons between topographic data sets. It also provides a means to improve measurement quality (Bertin et al. 2015), and hence to increase change detection capacity. To account for potential error types in SfM photogrammetry we used the following error model based on a sevenparameter Helmert transform (Carbonneau and Dietrich 2017):

$$
\mathrm{DSM}_{\mathrm{SfM}}=\mathrm{M}_{7} \mathrm{DSM}_{\text {true }}+\eta,
$$

where DSM $\mathrm{SfM}_{\mathrm{S}}$ is the DSM obtained using SfM photogrammetry and $\mathrm{DSM}_{\text {true }}$ is a ground truth representation of the surface (here the lidar DSM). The matrix factor $M_{7}$ represents the affine rigid-body seven-parameter Helmert transform needed to scale (one parameter: $S$ ), rotate (three parameters: $R x, R y, R z$ ), and translate (three parameters: Tx, Ty, Tz) DSM true $_{\text {to match }}$ $\mathrm{DSM}_{\mathrm{SfM}}$ in the least-squares sense. The value $\eta$ is a nonlinear, nonrigid error term approximating a quasi-random field representing noise in the photogrammetry. We used the standard deviation of $\eta$ (noted $\mathrm{SDE}_{\mathrm{SfM}}$ ) as a measure of precision (scatter) of $\mathrm{DSM}_{\mathrm{SfM}}$.

To ensure realistic error assessment that is not impacted by changes in topography, $\mathrm{DSM}_{\mathrm{SfM}}$ and $\mathrm{DSM}_{\text {true }}$ were compared over the back of the vegetated dune and grassy area

Table 1. Self-calibration outputs of SfM photogrammetry over the carpark area for the two reconstruction scenarios.

\begin{tabular}{lcccccccccc}
\hline & $\boldsymbol{f} \times \mathbf{1 0}^{\mathbf{3}}$ & $\boldsymbol{c} \boldsymbol{x} \times \mathbf{1 0}^{\mathbf{3}}$ & $\boldsymbol{c y} \times \mathbf{1 0}^{\mathbf{3}}$ & $\boldsymbol{K}_{\mathbf{1}} \times \mathbf{1 0}^{-\mathbf{9}}$ & $\boldsymbol{K}_{\mathbf{2}} \times \mathbf{1 0}^{-\mathbf{- 1 5}}$ & $\boldsymbol{K}_{\mathbf{3}} \times \mathbf{1 0}^{-\mathbf{2 2}}$ & $\boldsymbol{p}_{\mathbf{1}}$ & $\boldsymbol{p}_{\mathbf{2}}$ & $\mathbf{R M S}$ error & $\Delta(\mathbf{m})$ \\
\hline $\mathrm{UAS}_{\mathrm{GPS}}$ & 3.17 & 1.98 & 1.43 & 4.22 & -1.42 & 1.57 & 1.31 & 2.45 & 1.74 & 0.13 \\
\hline $\mathrm{UAS}_{\mathrm{GPS}}+\mathrm{GCP}$ & 3.17 & 1.98 & 1.43 & 4.23 & -1.42 & 1.57 & 1.24 & 2.43 & 1.74 & 0.09 \\
\hline
\end{tabular}

Note: All units are in pixels except where otherwise stated. $K_{\mathrm{n}}$ values reported by PhotoScan in focal length units were transformed to pixel units to facilitate comparison across studies. RMS error gives the root mean square reprojection error. $\Delta$ is the maximum range of vertical DSM deformation in comparison to a flat surface (cf., Figure 4). 
where little change was expected between the two surveys (this was confirmed by our measurements). To determine the parameters for $M_{7}$ using Matlab, four corresponding points easily identifiable with both photogrammetry and lidar were selected, and the different parameters that could transform $\mathrm{DSM}_{\text {true }}$ to match $\mathrm{DSM}_{\mathrm{SfM}}$ were calculated iteratively. We then determined $\eta$ by calculating the DoD between DSM true $_{\text {and }}$ and $\mathrm{DSM}_{\mathrm{SfM}}$ after the application of $\mathrm{M}_{7}$. The whole procedure was repeated several times to ascertain the reproducibility of our results. We also used the DoD to assess the presence of nonlinear deformations in photogrammetry by fitting a biquadratic surface that minimizes the difference between the DoD and the fitted trend in a least-squares sense.

Measurement quality was also assessed in comparison with the flat surface represented by a carpark located at the north end of the survey area (cf., Figure 1b). For this test, only the images surrounding the carpark were used and the same DSM reconstruction procedures as applied to the complete image data set were followed (cf., the section "SfM Photogrammetry Processing”). We assessed the presence of nonlinear deformations by first detrending linearly the DSM to produce a horizontal surface and then by fitting a biquadratic surface associated to doming or dishing.

\section{Results}

The following section examines the results of photogrammetry for the two reconstruction scenarios (i.e., with and without lidar-derived CtrlPts) on the simple test area provided by a carpark. For the two scenarios, we then determine the complete error model by comparing photogrammetry and lidar over a stable section of the survey area. Finally, we use the understanding of errors in photogrammetry to assess morphological and volume changes of the beachface and dune between 2013 and 2018, and to provide uncertainty bounds for the volumes obtained.

\section{Evaluation of Self-Calibration of SfM Photogrammetry}

Self-calibration outputs for the two reconstruction scenarios are presented in Table 1. Differences in calibration parameters are apparent for $K_{1}, p_{1}$, and $p_{2}$, which are coefficients for radial $\left(K_{1}\right)$ and tangential distortion $\left(p_{1}, p_{2}\right)$, respectively. Assuming the carpark area is approximately flat, small nonlinear deformations are observed for both scenarios. The UAS $\mathrm{GPS}_{\mathrm{BSM}}$ presents a concave curvature (Figure 4b), whilst a downward deformation occurred in the case of CtrlPts (Figure 4c). For the latter, we found the deformation to have a vertical range $\Delta$ $=0.09 \mathrm{~m}$ and a standard deviation $\sigma=0.0116 \mathrm{~m}$ (Figure 4e). A larger deformation was observed for $\mathrm{UAS}_{\mathrm{GPS}}$, with $\Delta=0.13 \mathrm{~m}$
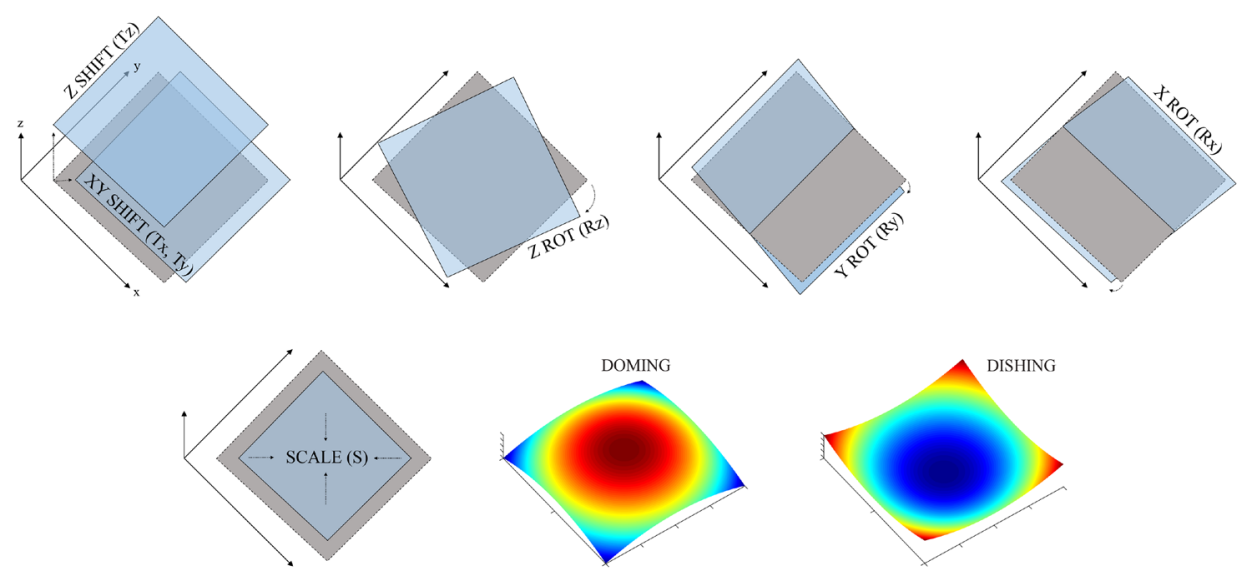

Figure 3. Schematic presentation of potential error types in SfM photogrammetry (adapted from Carbonneau and Dietrich 2017).
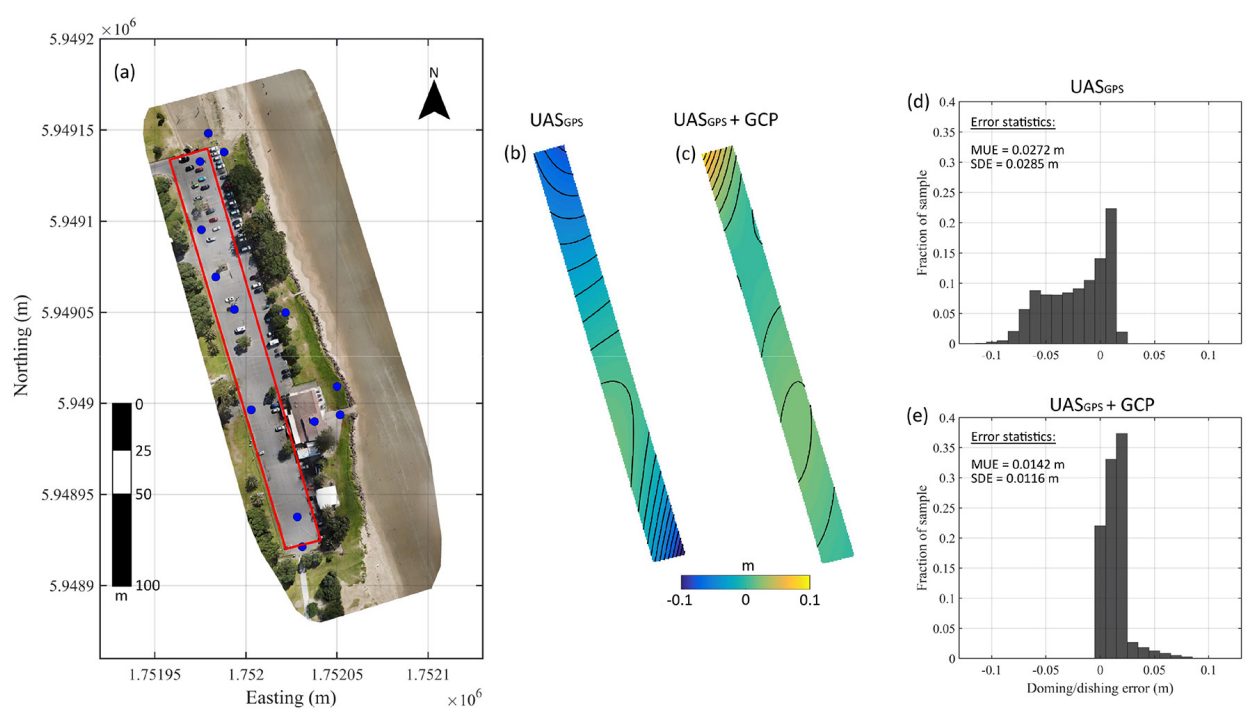

Figure 4. Evaluation of self-calibration of SfM photogrammetry for the two reconstruction scenarios. (a) Orthomosaic (GSD $\sim 0.01 \mathrm{~m}$ ) of the carpark area showing lidar-derived CtrlPts as blue dots; (b) DSM deformation for UAS GPS scenario (i.e., selfcalibration based on camera position only); (c) DSM deformation for $\mathrm{UAS}_{\mathrm{GPS}}+\mathrm{GCP}$ scenario (i.e., self-calibration based on

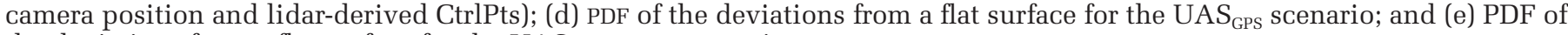
the deviations from a flat surface for the $\mathrm{UAS}_{\mathrm{GPS}}+\mathrm{GCP}$ scenario. 
and $\sigma=0.0285 \mathrm{~m}$ (Figure $4 \mathrm{~d}$ ). Using $\sigma$ as a proxy for measurement precision indicates higher precision when CtrlPts are used as weighted observations for bundle adjustment. For both scenarios, attempts were made to account for the rolling-shutter effect of the FC220 camera onboard the UAV by including affine distortion coefficients $(\mathrm{b} 1, \mathrm{~b} 2)$ during self-calibration. Despite small improvements in 3D camera positional error after bundle adjustment, the effect on DEM accuracy was less clear. For this reason, we were not able to conclude on the actual benefit of including the affine distortion coefficients, which were therefore omitted for the rest of the study.

\section{Error Assessment of SfM Photogrammetry Using Lidar as Control}

In Figure 5 we compare the DSMs obtained using photogrammetry and the (ground-truth) lidar DSM over the stable dune and grassy area at the Southwest of the study site. DoDs show that most of the surface ( $>80 \%$ in area) experienced morphological change less than $0.2 \mathrm{~m}$ (Figure $5 \mathrm{~d}$ and $4 \mathrm{e}$ ). The latter is the vertical precision of lidar. Observed changes between photogrammetry and lidar are consistent across the UAS $\mathrm{GPS}_{\mathrm{GP}}$ and the $\mathrm{UAS}_{\mathrm{GPS}}+\mathrm{GCP}$ reconstruction scenarios. Changes are associated to local variations in vegetation height between photogrammetry and lidar surveys. These variations essentially correspond to patches of vegetation that are higher in the DSMs obtained with photogrammetry, indicating vegetation growth locally between the two surveys. Analysis of the image data shows that the taller vegetation identified with photogrammetry corresponds to small perennial trees and shrubs. Other vegetation on the dune comprises different types of grass, low-growing succulents, and small scrambling shrubs common to coastal New Zealand (e.g., Spinifex sericeus, Ficinia spiralis, and Coprosma acerosa), which have limited growth.

DoDs indicate the presence of linear shifts (Figure $5 \mathrm{f}$ and $5 \mathrm{~g}$ ) and deformations (Figure $5 \mathrm{~h}$ and $5 \mathrm{i}$ ) of small magnitude (standard deviation $<0.2 \mathrm{~m}$ and vertical range $<0.5 \mathrm{~m}$ ). Linear shifts representing tilts between SfM photogrammetry and lidar vary depending on the reconstruction scenario used for photogrammetry. Tilt is more pronounced for $\mathrm{UAS}_{\mathrm{GPS}}$, with a vertical range of $0.34 \mathrm{~m}\left(0.06 \mathrm{~m}\right.$ in the case of $\left.\mathrm{UAS}_{\mathrm{GPS}}+\mathrm{GCP}\right)$. This tilt is essentially due to a rotation of the photogrammetry DSM along the $\mathrm{x}$-axis (easting), with rotation angles Rx of $0.0384^{\circ}$ and $0.0063^{\circ}$ for $\mathrm{UAS}_{\mathrm{GPS}}$ and $\mathrm{UAS}_{\mathrm{GPS}}+\mathrm{GCP}$ scenarios, respectively, which corresponds to a six-fold improvement when using CtrlPts (Table 2). The improvement is less for tilts along the y-axis (northing), with Ry values of $0.0332^{\circ}$ and $0.0237^{\circ}$ (i.e., a 1.4-time improvement, Table 2), for $\mathrm{UAS}_{\mathrm{GPS}}$ and $\mathrm{UAS}_{\mathrm{GPS}}+\mathrm{GCP}$ scenarios, respectively. Figure 5a shows that CtrlPts were well spread along the y direction, but less along $\mathrm{x}$, due to the nature of the site and flight plan. Supporting previous findings that ground control should ideally be distributed across the whole survey area (James et al. 2017; Martínez-Carricondo et al. 2018), the uneven repartition of CtrlPts potentially explains why the reduction of tilt was more significant alongshore, i.e., along the x-axis.

Improvements are observed for the other parameters of the error model adopted in this study (Table 2). Translation errors are reduced by $\sim 10 \%$ when using CtrlPts, from an initial multidirectional error $\mathrm{T}=\left(\mathrm{Tx}^{2}+\mathrm{Ty}^{2}+\mathrm{Tz}^{2}\right)^{0.5}$ of $0.45 \mathrm{~m}$ for $\mathrm{UAS}_{\mathrm{GPS}}$ to $0.40 \mathrm{~m}$ for $\mathrm{UAS}_{\mathrm{GPS}}+\mathrm{GCP}$. Horizontal rotation Rz improved by two orders of magnitude between the two scenarios, while scale remained approximately constant at around $100 \%$ of the
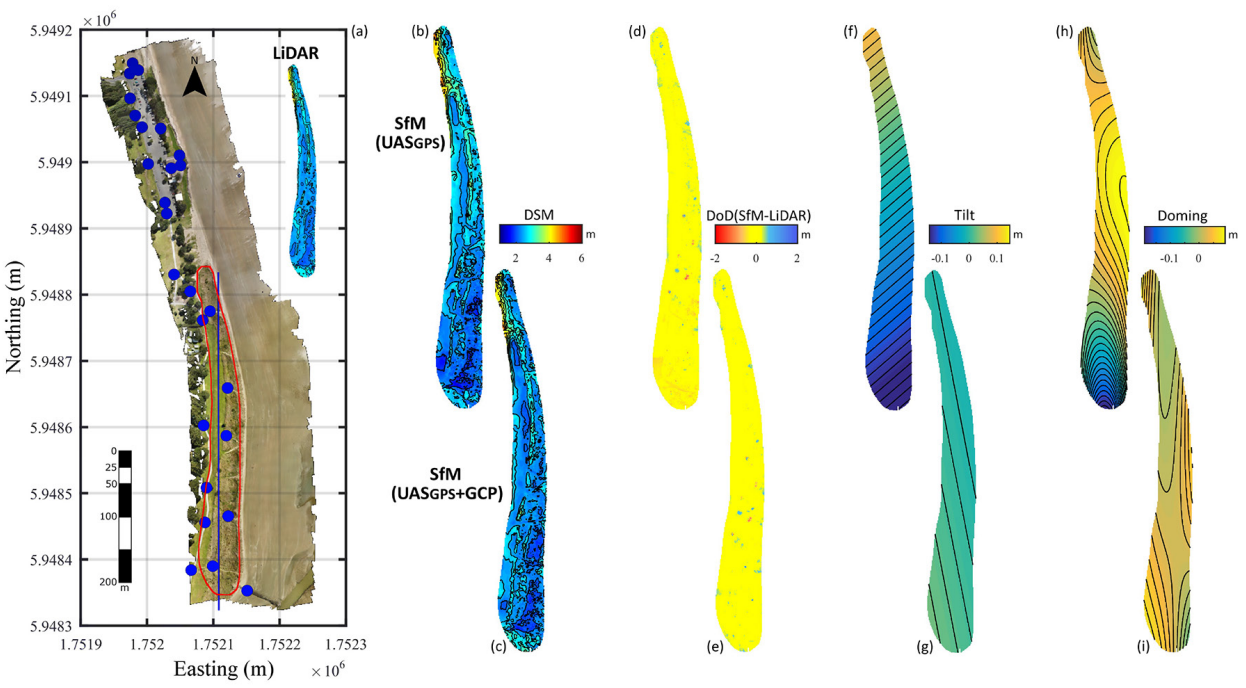

Figure 5. Accuracy assessment of photogrammetry using lidar as control. (a) Orthomosaic (GSD $\sim 0.1 \mathrm{~m}$ ) showing the vegetated dune and grassy area circled in red where the evaluation is performed, lidar derived CtrlPts as blue dots, and the transect (vertical line) used for further evaluation in Figure 6. The subset at the top right shows the "ground truth" lidar DSM. (b-c) DSMs obtained using photogrammetry for the $\mathrm{UAS}_{\mathrm{GPS}}$ and UAS $\mathrm{UPS}_{\mathrm{G}}+\mathrm{GCP}$ scenarios, respectively. (d-e) Resulting DoDs between photogrammetry and LiDAR. (f-g) Planar trends identified in DoDs (step level = 0.01 m). (h-i) Biquadratic trends identified in DoDs (step level $=0.01 \mathrm{~m}$ ). All dimensions are in meters.

Table 2. Error parameters for the two reconstruction scenarios used for SfM photogrammetry.

\begin{tabular}{lccccccc}
\hline & Tx (m) & Ty (m) & Tz (m) & $\mathbf{R x ~}\left(^{\circ}\right)$ & $\mathbf{R y ~}\left(^{\circ}\right)$ & $\mathbf{R z}\left({ }^{\circ}\right)$ & $\mathbf{S}(\%)$ \\
\hline $\mathrm{UAS}_{\mathrm{GPS}}$ & 0.18 & -0.41 & -0.08 & 0.038 & 0.033 & -0.270 & 100.32 \\
\hline $\mathrm{UAS}_{\mathrm{GPS}}+\mathrm{GCP}$ & -0.38 & 0.16 & 0.02 & 0.006 & 0.024 & -0.002 & 100.16 \\
\hline
\end{tabular}

Note: Error is assessed in comparison with lidar over the vegetated dune and grass area. Tx and Ty are horizontal shifts; Tz is vertical shift (positive value shows SfM above lidar), estimated as the mean deviation over all DSM points. Rx, Ry, and Rz are solid rotations with respect to $\mathrm{x}, \mathrm{y}$, and $\mathrm{z}$ axes (therefore $\mathrm{Rz}$ is the horizontal rotation; $\mathrm{Rx}$ and Ry are deviations from the horizontal). S is scale in percent of lidar DSM $(100 \%$ means identical scale). Axes $\mathrm{x}, \mathrm{y}$, and $\mathrm{z}$ are easting, northing, and vertical directions, respectively. 
actual size. Similar to tilt-related errors, warp (i.e., nonlinear deformation) is more pronounced for the $\mathrm{UAS}_{\mathrm{GPS}}$ scenario, with a vertical range of $0.26 \mathrm{~m}$ compared to $0.1 \mathrm{~m}$ after adding CtrlPts (Figure 5h and 5i). These nonlinear deformations are consistent with our previous observations for the carpark area (Figure 4b and 4c). It shows a concave curvature (dome) for $\mathrm{UAS}_{\text {GPS }}$ (Figure 5h) and a more complex shape with lower amplitude crests and troughs in the $\mathrm{UAS}_{\mathrm{GPS}}+\mathrm{GCP}$ DSM (Figure 5i).

To better understand the effects of tilts and warps in photogrammetry, elevation differences in comparison with lidar are plotted for a single transect traversing the dune North to South (Figure 6b and 6d). It shows that both linear and nonlinear deformations in the $\mathrm{UAS}_{\mathrm{GPS}}$ DSM contribute to deviations from the lidar profile and that correction of the two error types (by removing trends identified in the DoD) is necessary to obtain a bed-elevation profile structurally similar to lidar (Figure 6b). This is shown in the probability distribution functions (PDFs) of vertical disparities (Figure 6a) by a higher peak and more centered distributions after tilt and warp removal. Quantitatively, Table 3 shows improving DSM accuracy (i.e., a reduction of errors) when DSMs are detrended to remove planar and nonlinear trends. In comparison to the $\mathrm{UAS}_{\mathrm{GPS}}$ scenario, virtually no improvement resulted from removing planar and nonlinear trends in the case of the UAS + GCP DSM (Figure 6c and 6d, Table 3), suggesting that tilt and warp errors play a minor role to explain the differences between SfM photogrammetry and lidar when using CtrlPts. In this case, differences are in part due to different measurement resolutions $(0.1 \mathrm{~m}$ and $1 \mathrm{~m}$ for SfM photogrammetry and lidar, respectively), with SfM photogrammetry allowing for a more detailed terrain representation in comparison to lidar. Our results show that the improved resolution with SfM photogrammetry is not counterbalanced by increasing noise in the data (see smoother parts of the profile, Figure 6d).
Application to Geomorphic Change Detection Between 2013 and 2018 In Figure 7 we present orthomosaics and DSMs of the dune and beachface obtained during UAS photogrammetry and lidar surveys in 2018 and 2013, respectively. The photogrammetric DSMs obtained using both $\mathrm{UAS}_{\mathrm{GPS}}$ and $\mathrm{UAS}_{\mathrm{GPS}}+\mathrm{GCP}$ are presented to assess the effect of reconstruction scenarios on geomorphic change detection. Morphological changes are essentially located on the beachface and show a nonuniform distribution alongshore. As observed previously (Figure 5), the dune area experienced little change at the exception of the incipient foredune (which was not included in the previous analysis limited to the stable area of the dune), where positive elevation changes (shown in blue) indicate the stabilization of sediment and the apparition of vegetation between 2013 and 2018. Contrasting this observation, the erosion of sand can be observed up to the rip-rap seawall, suggesting the positive effect of the vegetated dune for mitigating erosion along this part of the beach. Although morphological change calculated using the two reconstruction scenarios follows a similar pattern, disparities exist in places. This is especially the case at the northern end of the study area and at the easternmost border (between northing distances 5.9485 and $5.9486 \times 10^{6} \mathrm{~m}$ ) where a red blob in Figure $7 \mathrm{~g}$ indicates more severe erosion for the $\mathrm{UAS}_{\mathrm{GPS}}+\mathrm{GCP}$ scenario.

The effect of the reconstruction scenario used for photogrammetry on volumetric change is illustrated in Figure 7h, which shows the volume eroded per meter of beach length. The volume of eroded sediment computed was larger for the $\mathrm{UAS}_{\mathrm{GPS}}+\mathrm{GCP}$ scenario (Table 4), with a volume amounting to $39428 \pm 13874 \mathrm{~m}^{3}$ compared to $31833 \pm 18710 \mathrm{~m}^{3}$ for the $\mathrm{UAS}_{\mathrm{GPS}}$ scenario. Both scenarios indicate a negative sediment budget for the period, with deposition volumes only amounting to $1087.27 \pm 794 \mathrm{~m}^{3}$ for the $\mathrm{UAS}_{\mathrm{GPS}}$ scenario and $744 \pm 543$ $\mathrm{m}^{3}$ for the $\mathrm{UAS}_{\mathrm{GPS}}+\mathrm{GCP}$ scenario. For both scenarios, there is a large volumetric uncertainty, with uncertainties potentially amounting to more than $50 \%$ of the volumes computed.
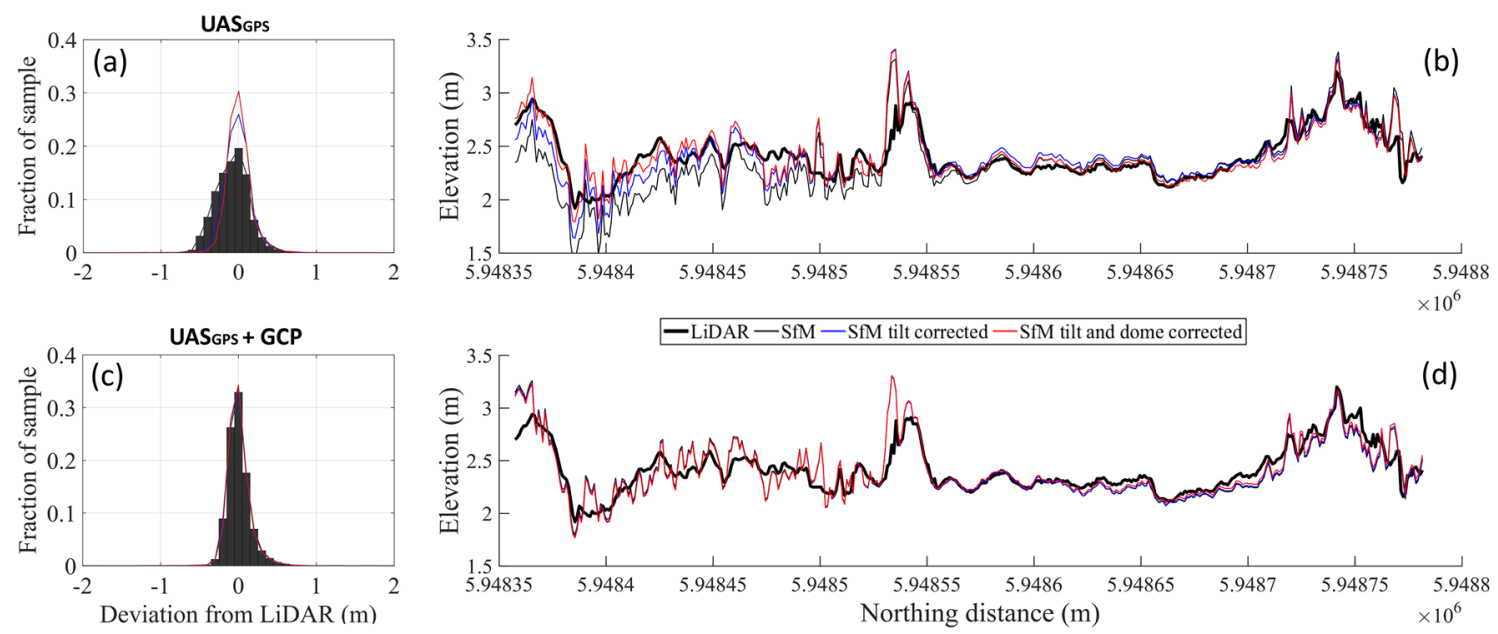

Figure 6. Comparison of photogrammetry and lidar elevations for the two photogrammetric reconstruction scenarios, before and after correction of tilt and warp errors. (a-c) PDFs of vertical disparity between photogrammetry and lidar DSMs for

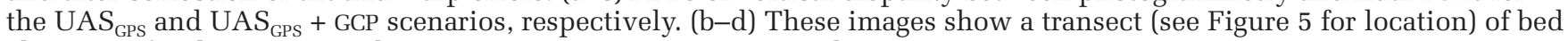
elevations for the $\mathrm{UAS}_{\mathrm{GPS}}$ and $\mathrm{UAS}_{\mathrm{GPS}}+$ GCP scenarios, respectively.

Table 3. Accuracy assessment of photogrammetry.

\begin{tabular}{lccc|ccc|cc}
\hline & \multicolumn{3}{c}{ Original DSM } & \multicolumn{3}{c|}{ Tilt corrected } & \multicolumn{2}{c}{ Tilt + doming corrected } \\
& ME & MUE & SDE $_{\text {SM }}$ & ME & MUE & SDE & ME & MUE \\
\hline $\mathrm{UAS}_{\mathrm{GPS}}$ & -0.083 & 0.181 & 0.221 & -0.008 & 0.129 & 0.178 & 0.0002 & 0.113 \\
\hline $\mathrm{UAS}_{\mathrm{GPS}}+\mathrm{GCP}$ & 0.017 & 0.108 & 0.156 & 0.004 & 0.105 & 0.154 & 0.003 & 0.102 \\
\hline
\end{tabular}

Note: Accuracy is assessed by comparing photogrammetric and lidar DSMs over the dune and grass area. All units are in meters. ME, MUE, and SDE correspond to mean error, mean unsigned error, and standard deviation of error estimated over the complete DSM. 

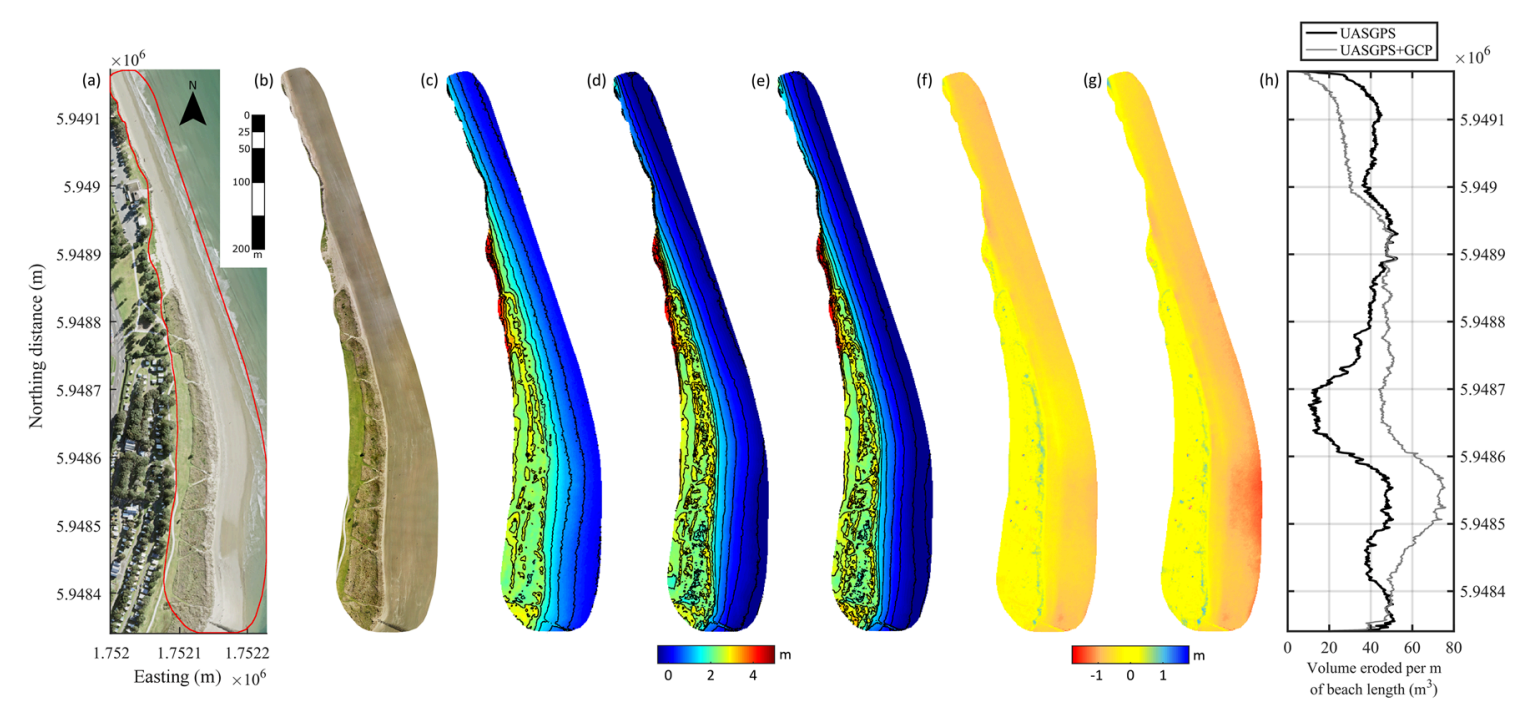

Figure 7. Analysis of morphological change and volumes eroded between lidar (2013) and UAS photogrammetry (2018) surveys. Orthomosaics for the (a) 2013 survey and (b) the 2018 survey. (c) DSMs for the lidar survey, (d) photogrammetric

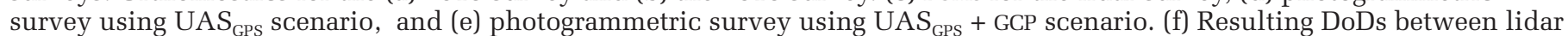
and $\mathrm{UAS}_{\mathrm{GPS}}$ and $(\mathrm{g})$ between lidar and $\mathrm{UAS}_{\mathrm{GPS}}+\mathrm{GCP}$. (h) Continuous evaluation of volumes eroded per meter section of beach for the two reconstruction scenarios.

These uncertainties were unavoidable firstly because of a lidar precision of $0.2 \mathrm{~m}$. Volumetric changes between 2013 and 2018 were also computed without thresholding to assess the effect of a minLOD on change detection capacity. In terms of the net volume change (Table 4), the volumes computed with and without thresholding differed by $5 \%$ and $0.6 \%$ for the $\mathrm{UAS}_{\mathrm{GPS}}$ and the $\mathrm{UAS}_{\mathrm{GPS}}+\mathrm{GCP}$ scenario, respectively. This suggests minLOD has a relatively small effect on volumetric changes computed in this study, and more reliable measurements when using CtrlPts.

\section{Discussion}

Previous research reported that the requirement to acquire ground control with survey-grade equipment remains the predominant barrier, both in terms of time and cost, to the larger uptake of UAS photogrammetry (e.g., Carbonneau and Dietrich 2017; Chudley et al. 2019). The results produced in this paper showcase the possibility to obtain satisfactory topographic data to study coastal change using a consumer UAS and standard SfM photogrammetry software, without having to presurvey targets (GCPs) distributed on the study site. The method implemented, called DG, enables georeferenced and scaled measurements from knowledge of camera position and orientation at the time of image acquisition. The method is used to assess morphological change at Orewa Beach, a sandy beach with low topographic variance. Using DG, footaccess to the study site to install and locate GCPs is no longer necessary. Besides considerably reducing the time and cost of field operations, DG takes full advantage of UAS ability to operate in difficult and remote terrains that would otherwise be a challenge to access with standard surveying equipment. For the study of coastal systems, where hazards to field personnel and equipment exist, DG from consumer UAS presents an enviable alternative to photogrammetric approaches requiring GCPs and to bulkier and more expensive surveying techniques such as terrestrial laser scanners.

In the absence of accurate ground control, various types of errors (e.g., related to position, orientation, and shape) can be introduced in topographic data produced with SfM photogrammetry. It is important to know the source, magnitude,
Table 4. Volumetric change between lidar (2013) and UAS photogrammetry (2018) surveys without thresholding $(\mathrm{minLOD}=$ 0) and using the error estimates obtained during the assessment.

\begin{tabular}{lcccc}
\hline & $\begin{array}{c}\operatorname{minLOD} \\
(\mathbf{m})\end{array}$ & $\begin{array}{c}\text { Erosion } \\
\left(\mathbf{m}^{3}\right)\end{array}$ & $\begin{array}{c}\text { Deposition } \\
\left(\mathbf{m}^{\mathbf{3}}\right)\end{array}$ & $\begin{array}{c}\text { Net change } \\
\left(\mathbf{m}^{\mathbf{3}}\right)\end{array}$ \\
\hline \multirow{2}{*}{$\mathrm{UAS}_{\mathrm{GPS}}$} & 0.58 & $31833 \pm 18710$ & $1087.27 \pm 794$ & -30745 \\
& 0 & 35410 & 3014 & -32396 \\
\hline \multirow{2}{*}{$\mathrm{UAS}_{\mathrm{GPS}}+\mathrm{GCP}$} & 0.49 & $39428 \pm 13874$ & $744 \pm 543$ & -37760 \\
& 0 & 40517 & 2538 & -37979 \\
\hline
\end{tabular}

and occurrence of these errors as it determines the capacity to detect morphological change using the data, and when possible, it should be attempted to mitigate the impact on data analysis. When using consumer-grade UAS, it is recommended to replace the camera absolute elevations with relative elevations from the internal barometer, as barometer readings produce more precise vertical estimates than GPS (Funaki and Hirasawa 2008; Bao et al. 2017). Achieving satisfactory camera elevation is critical to achieving good camera calibration and hence good results with SfM photogrammetry. Erroneous camera elevations lead to incorrect focal length estimates during self-calibration (Griffiths and Burningham 2019), with at least two major consequences. First, when computing depth maps from the matched points in images, focal length is a crucial parameter in the triangulation process, with slight errors in focal length potentially resulting in large errors in depth estimates. Second, focal length is the primary parameter estimated during bundle adjustment, with errors in focal length rendering the optimization of other calibration parameters incorrect. The effect is a systematic deformation taking the form of doming or dishing (Figure 3).

Small deformations were observed in our DSMs (Figures 4-7); yet, these could only be evidenced after careful comparison with a ground truth. For the DSM of the back of the dune (Figure $5 \mathrm{~h}$ ), we found deformations with a maximum range of $0.26 \mathrm{~m}$. This is significantly less than the deformation observed in the DSM of a salt marsh (Griffiths and Burningham 2019), which was produced from single-scale nadironly images (maximum vertical error $>2 \mathrm{~m}$ in Griffiths and 
Burningham (2019) Figure 4 "Photoscan UAS ${ }_{\text {GPS }}$ Auto-cal"). This therefore agrees with previous research (e.g., Wackrow and Chandler 2008; James and Robson 2014; Carbonneau and Dietrich 2017) that when self-calibration is employed, oblique imagery is more effective at mitigating systematic distortion than vertical imagery. Orientation errors, such as tilts with respect to $\mathrm{x}$ - and $\mathrm{y}$-axes and rotation along $\mathrm{z}$ were also present in DSMs (Table 2) and accounted for more of the overall DSM error than nonlinear deformations (Table 3). Despite these caveats, our evaluations show that a high DSM accuracy can be achieved using DG, which is exemplified here by MUE $=0.181$ $\mathrm{m}$ and SDE $=0.221 \mathrm{~m}$ after comparing our results with lidar (Table 3). These values correspond to accuracies reported in previous coastal studies using GCPs and standard surveying equipment (Long et al. 2016; Laporte-Fauret et al. 2019).

Adding CtrlPts as weighted observations in the bundle adjustment increased the overall DSM accuracy (Table 3), indicated by $\mathrm{MUE}=0.108 \mathrm{~m}$ and $\mathrm{SDE}=0.156 \mathrm{~m}$ (i.e., a $41 \%$ and $29 \%$ improvement compared to the case without CtrlPts, respectively), and a reduction of all errors measured in this study. When using CtrlPts, incorrect orientations and model deformations played a minor role to explain the differences between photogrammetry and lidar (Figure 6), with only a $3 \%$ reduction in SDE after removing tilt and warp from the topographic data (Table 3 ). This is in contrast to the $27 \%$ reduction in SDE after tilt and warp were removed from the UAS data set. CtrlPts can be extracted from existing data sets such as lidar or SRTM (Carbonneau and Dietrich 2017). Datasets like these are increasingly available to determine 3D ground coordinates worldwide. Ideally, CtrlPts should be selected in areas of low-topographic variance and using sharp features to avoid introducing georeferencing errors. Two to three carefully selected CtrlPts (i.e., with a distance between points that covers as much of the site diagonally as possible) are sufficient, in theory, to correct orientation errors in DSMs (Carbonneau and Dietrich 2017; Dering et al. 2019). In practice, this also requires a high-level of confidence in CtrlPts' vertical estimate, as even slight errors will naturally affect photogrammetric results due to angle uncertainties (Ouédraogo et al. 2014; Li, Bertin, and Friedrich 2018). A large number of CtrlPts (26) were used in this study to compensate uncertainties caused by lidar ( $0.2 \mathrm{~m}$ vertical). In light of our results, this was justified by the differential reduction in orientation error between $\mathrm{x}$ and $\mathrm{y}$ directions (Table 2), which showed that having a good repartition of CtrlPts is important to correct linear shifts.

In addition to using CtrlPts, other strategies could be attempted to reduce measurement uncertainties in future studies. The most important component of photogrammetric surveys is the quality of the camera (Mosbrucker et al. 2017; Laporte-Fauret et al. 2019). With consumer-grade UAS now equipped with professional cameras (e.g., a 20-megapixel Hasselblad camera onboard the MP2), or capable of independent camera fittings for a digital single-lens reflex camera (e.g., DJI Inspire), increased accuracy could be achieved due to better optics and higher resolution than common point and shoot cameras (Turner, Lucieer, and Wallace 2014). Camera precalibration using either a chequerboard (Li, Bertin, and Friedrich 2018; Griffiths and Burningham 2019) or a flat wall (Carbonneau and Dietrich 2017) could also increase the quality of topographic data in comparison to using self-calibration by reducing nonlinear deformations resulting from poorly modeled lens distortion. Finally, improving camera position (e.g., with newer consumer UAS using RTK-GPS or by postprocessing simple dual-frequency GNSS data to a nearby base) will likely continue to improve the quality of topographic data obtained using DG. Nevertheless, the results at hand already demonstrate the possibility to use SfM photogrammetry and consumer-grade equipment to obtain high-quality topographic data, which will be suitable for a range of applications. For the measurement of coastal topography, it is imagined that using DG from consumer UAS will ultimately allow local governments and other stakeholders to set up regular beach monitoring, without requiring access to national mapping agencies or more expensive surveying techniques.

\section{Conclusions}

In this paper, we have evaluated the effectiveness of a DG approach, and imagery obtained from a consumer-grade UAS, for the cost-effective monitoring of beach morphological change with SfM photogrammetry. The method uses camera positions derived from an on-board GNSS receiver and barometer to compute georeferenced orthophotos and DSMs (rasterized point clouds) of the surveyed area, while obviating the need for on-site target installation and independent georeferencing (GCPs). Using the south end of Orewa Beach (New Zealand) as a field laboratory, we have shown that vertical accuracies similar to lidar $(<0.2 \mathrm{~m})$ can be obtained using DG, at a higher resolution $(<0.1 \mathrm{~m})$. Our results also compare favorably with previous studies using SfM photogrammetry and networks of GCPs. Low-quality GNSS modules currently onboard consumer UAS remain the main constraint on measurement quality, for instance by introducing measurement artifacts such as linear shifts and geometric distortions. To mitigate these effects, we have shown that CtrlPts extracted from available topographic data sets can increase measurement quality, providing reliable data to assess morphological change.

Although not yet able to completely eliminate the need for ground control for higher accuracy, DG from consumer-grade UAS already offers the possibility to obtain high-quality topographic data with a time and cost efficiency virtually unsurpassed by concurrent surveying techniques. It will benefit academic and nonacademic circles from a large range of disciplines, for which topographic data are increasingly valuable. In application to the coastal zone, DG could allow increases in the frequency of data acquisition to monitor beach change, and more widespread applications in hazardous and/or fragile (eco)systems including, but not limited to, erodible cliffs, gravel spits, and sand dunes.

\section{Acknowledgments}

The authors would like to thank the editor, Alper Yilmaz, and the anonymous reviewer for their valuable comments, which helped to improve the paper. The first author is also grateful to the coastal team at Auckland council for sharing insights on the monitoring program conducted at Orewa Beach and for discussion.

\section{References}

Bao, X., Z. Xiong, S. Sheng, Y. Dai, S. Bao and J. Liu. 2017. Barometer measurement error modeling and correction for UAH altitude tracking. Pages 3166-3171 in the Proceedings of the 29th Chinese Control and Decision Conference (CCDC), held in Chongqing, China, 28-30 May 2017. <https://doi.org/10.1109/ CCDC.2017.7979052>.

Bertin, S., H. Friedrich, P. Delmas, E. Chan and G. Gimel'farb. 2015. Digital stereo photogrammetry for grain-scale monitoring of fluvial surfaces: Error evaluation and workflow optimization. ISPRS Journal of Photogrammetry and Remote Sensing 101:193208. <https://doi.org/10.1016/j.isprsjprs.2014.12.019>.

Bertin, S., H. Friedrich and P. Delmas. 2016. A merging solution for close-range DEMs to optimize surface coverage and measurement resolution, photogrammetric engineering and remote sensing. Photogrammetric Engineering and Remote Sensing 82 (1):31-40. $<$ https://doi.org/10.14358/pers.83.1.31>. 
Brasington, J., J. Langham and B. Rumsby. 2003. Methodological sensitivity of morphometric estimates of coarse fluvial sediment transport. Geomorphology 53:299-316. <http://dx.doi. org/10.1016/S0169-555X(02)00320-3>.

Carbonneau, P. E. and J. T. Dietrich. 2017. Cost-effective non-metric photogrammetry from consumer-grade sUAS: Implications for direct georeferencing of structure from motion photogrammetry. Earth Surface Processes and Landforms 42:473-486. <https:// doi.org/10.1002/esp.4012>.

Chudley, T. R., P. Christoffersen, S. H. Doyle, A. Abellan and N. Snooke. 2019. High-accuracy UAV photogrammetry of ice sheet dynamics with no ground control. The Cryosphere 13:955-968. $<$ https://doi.org/10.5194/tc-13-955-2019>.

Colomina, I. and P. Molina. 2014. Unmanned aerial systems for photogrammetry and remote sensing: A review. ISPRS Journal of Photogrammetry and Remote Sensing 92:79-97. <https://doi. org/10.1016/j.isprsjprs.2014.02.013>.

Dering, G. M., S. Micklethwaite, S. T. Thiele, S. A. Vollgger and A. R. Cruden. 2019. Review of drones, photogrammetry and emerging sensor technology for the study of dykes: Best practises and future potential. Journal of Volcanology and Geothermal Research 373:148-166. <https://doi.org/10.1016/j. jvolgeores.2019.01.018>.

Funaki, M. and N. Hirasawa. 2008. Outline of a small unmanned aerial vehicle (Ant-Plane) designed for Antarctic research. Polar Science 2:129-142. <https://doi.org/10.1016/j. polar.2008.05.002>.

Furukawa, Y. and J. Ponce. 2010. Accurate, dense, and robust multiview stereopsis. IEEE Transactions on Pattern Analysis and Machine Intelligence 32:1362-1376. <https://doi.org/10.1109/ TPAMI.2009.161>

Griffiths, D. and H. Burningham. 2019. Comparison of pre- and self-calibrated camera calibration models for UAS-derived nadir imagery for a SfM application. Progress in Physical Geography: Earth and Environment 43:215-235. <https://doi. org/10.1177/0309133318788964>.

Ierodiaconou, D., A.C.G. Schimel and D. M. Kennedy. 2016. A new perspective of storm bite on sandy beaches using Unmanned Aerial Vehicles. Zeitschrift für Geomorphologie 60:123-137. $<$ https://doi.org/10.1127/zfg_suppl/2016/00247>.

James, M. R. and S. Robson. 2014. Mitigating systematic error in topographic models derived from UAV and ground-based image networks. Earth Surface Processes and Landforms 39:14131420. <https://doi.org/10.1002/esp.3609>.

James, M. R., S. Robson, S. d'Oleire-Oltmanns and U. Niethammer. 2017. Optimising UAV topographic surveys processed with structure-from-motion: Ground control quality, quantity and bundle adjustment. Geomorphology 280:51-66. <https://doi. org/10.1016/j.geomorph.2016.11.021>.

James, M. R., S. Robson and M. W. Smith. 2017. 3-D uncertaintybased topographic change detection with structure-from-motion photogrammetry: Precision maps for ground control and directly georeferenced surveys. Earth Surface Processes and Landforms 42:1769-1788. <https://doi.org/10.1002/esp.4125>.

Jaud, M., N. Le Dantec, J. Ammann, P. Grandjean, D. Constantin, Y. Akhtman, K. Barbieux, K. Allemand, C. Delacourt and B. Merminod. 2018. Direct georeferencing of a pushbroom, lightweight hyperspectral system for mini-UAV applications. Remote Sensing 10:204. <https://doi.org/10.3390/rs10020204>.

Lane, S. N., T. D. James and M. D. Crowell. 2000. Application of digital photogrammetry to complex topography for geomorphological research. Photogrammetric Record 16:793821. <https://doi.org/10.1111/0031-868x.00152>.
Laporte-Fauret, Q., V. Marieu, B. Castelle, R. Michalet, S. Bujan and D. Rosebery. 2019. Low-cost UAV for high-resolution and largescale coastal dune change monitoring using photogrammetry. Journal of Marine Science and Engineering 7:63. <https://doi. org/10.3390/jmse7030063>.

Land Information New Zealand (LINZ). <https://www.linz.govt.nz/> Accessed 16 July 2019.

Li, W., S. Bertin and H. Friedrich. 2018. Combining structure from motion and close-range stereo photogrammetry to obtain scaled gravel bar DEMs. International Journal of Remote Sensing 39:9269-9293. <https://doi.org/10.1080/01431161.2018.1530809>.

Long, N., B. Millescamps, B. Guillot, F. Pouget and X. Bertin. 2016. Monitoring the topography of a dynamic tidal inlet using UAV imagery. Remote Sensing 8:387. <https://doi.org/10.3390/ rs8050387>.

Lowe, D. G. 2004. Distinctive image features from scale-invariant keypoints. International Journal of Computer Vision 60:91-110. <https://doi.org/10.1023/B:VISI.0000029664.99615.94>.

Mancini, F., M. Dubbini, M. Gattelli, F. Stecchi, S. Fabbri and G. Gabbianelli. 2013. Using unmanned aerial vehicles (UAV) for high-resolution reconstruction of topography: The structure from motion approach on coastal environments. Remote Sensing 5:6880-6898. <https://doi.org/10.3390/rs5126880>.

Martínez-Carricondo, P., F. Agüera-Vega, F. Carvajal-Ramírez, F.-J. Mesas-Carrascosa, A. García-Ferrerand and F.-J. Pérez-Porras. 2018. Assessment of UAV-photogrammetric mapping accuracy based on variation of ground control points. International Journal of Applied Earth Observation and Geoinformation 72:1-10. <https://doi.org/10.1016/j.jag.2018.05.015>.

Ministry for the Environment. 2015. Preparing New Zealand for rising Seas: Certainty and Uncertainty.

Mosbrucker, A. R., J. J. Major, K. R. Spicer and J. Pitlick. 2017. Camera system considerations for geomorphic applications of SfM photogrammetry. Earth Surface Processes and Landforms 42:969-986. <https://doi.org/10.1002/esp.4066>.

National Institute of Water and Atmosphere. 2015. National and Regional Risk-Exposure in Low-Lying Coastal Areas: Areal Extent, Population, Buildings and Infrastructure. Report prepared for Parliamentary Commissioner for the Environment.

Ouédraogo, M. M., A. Degré, C. Debouche and J. Lisein. 2014. The evaluation of unmanned aerial system-based photogrammetry and terrestrial laser scanning to generate DEMs of agricultural watersheds. Geomorphology 214:339-355. <http://dx.doi. org/10.1016/j.geomorph.2014.02.016>.

Raji, O., L. Del Río, F. J. Gracia and J. Benavente. 2011. The use of LIDAR data for mapping coastal flooding hazard related to storms in Cádiz Bay (SW Spain). Journal of Coastal Research: 1881-1885.

Raudkivi, A. 1981. Orewa Beach Investigation. Report prepared for Rodney District Council.

Talavera, L., L. Del Río, J. Benavente, L. Barbero and J. A. LópezRamírez. 2018. UAS as tools for rapid detection of storminduced morphodynamic changes at Camposoto Beach, SW Spain. International Journal of Remote Sensing 39:5550-5567. $<$ https://doi.org/10.1080/01431161.2018.1471549>.

Turner, D., A. Lucieer and L. Wallace. 2014. Direct georeferencing of ultrahigh-resolution UAV imagery. IEEE Transactions on Geoscience and Remote Sensing 52:2738-2745. <https://doi. org/10.1109/TGRS.2013.2265295>.

Turner, I. L., M. D. Harley and C. D. Drummond. 2016. UAVs for coastal surveying. Coastal Engineering 114:19-24. <https://doi. org/10.1016/j.coastaleng.2016.03.011>.

Wackrow, R. and J. H. Chandler. 2008. A convergent image configuration for DEM extraction that minimises the systematic effects caused by an inaccurate lens model. Photogrammetric Record 23:6-18. <https://doi.org/10.1111 /j.1477-9730.2008.00467>. 